\title{
AFONSO X E A LEGITIMAÇÃO DO PODER REAL NAS CANTIGAS DE SANTA MARIA
}

Marina Kleine

\begin{abstract}
RESUMO
Estudo da imagem do rei nas Cantigas de Santa Maria, com ênfase nos qualificativos atribuídos ao rei, a propaganda e defesa de sua pretensão ao trono do Sacro Império, a legitimação de sua linhagem e, especialmente, o tratamento reservado à questão da natureza sagrada do poder real. $O$ objetivo é contribuir com a discussão entre hispanistas (Adeline Rucquoi, Arias Bonet, Teófilo Ruiz) a respeito da especificidade da monarquia castelhana no no tocante aos fundamentos religiosos de seu poder.
\end{abstract}

As Cantigas de Santa Maria, compiladas na corte de Afonso $\mathrm{X}^{1}$, constituem um corpus de 420 poemas musicados, encontrados nos quatro diferentes manuscritos de que temos notícia ${ }^{2}$. Seu valor artístico é indiscutível: trata-se da maior fonte de música medieval ibérica não-litúrgica e do maior conjunto de poemas medievais redigidos em galegoportuguês, agrupados de forma a constituir uma obra ${ }^{3}$. Todavia, nos últimos anos, vem sendo também reconhecido o valor das cantigas como fonte histórica através do trabalho especializado de autores como Joseph F. O'Callaghan ${ }^{4}$, Robert I. Burns ${ }^{5}$, Richard P. Kinkade ${ }^{6}$, Jesús Montoya Martínez $z^{7}$, entre outros. De fato, o conjunto dos poemas constitui uma riquíssima fonte de informações não só sobre diversos aspectos da sociedade ibérica à época do "rei sábio", mas também sobre fatos importantes ocorridos durante seu reinado e até mesmo sobre questões pessoais a respeito de sua própria vida e de sua família.

As Cantigas nos informam, por exemplo, sobre a ascendência do rei, suas atitudes em relação aos mouros, a natureza do conflito entre cristãos e mouros, seu projeto de Cruzada ao Marrocos, a invasão da Espanha por Marrocos e as tentativas de repovoamento

Marina Kleine é Graduanda de Letras pelo Instituto de Letras da UFRGS. 
de Cádiz e do Porto de Santa Maria; mas acima de tudo, elas revelam os sentimentos do rei em relação à deslealdade da nobreza, às suas freqüentes doenças e ao seu medo do fogo do inferno e da danação eterna. A Virgem Maria aparece em toda a obra como sua advogada, protetora e consoladora. Através de seus atos maravilhosos, o rei acreditava poder triunfar sobre seus inimigos e adversidades que o cercavam dentro e fora de seus reinos. Ao mesmo tempo em que não precisamos compartilhar de sua crença em milagres ou no papel ativo desempenhado pela Virgem em sua vida e na de seu reino, podemos aceitar como autênticos a essência e muitos dos detalhes das histórias que ele nos conta. ${ }^{8}$

Dito isso, partindo destas palavras de O'Callaghan, mas sem esquecer a natureza desta obra literária repleta de lendas piedosas e histórias de milagres, com seu caráter lendário e ficcional, o objetivo deste trabalho é propor uma abordagem da obra que permita considerá-la como parte não apenas das empresas artísticas de Afonso X, mas também do seu projeto político de centralização ${ }^{9}$, aspecto bastante evidente em suas obras jurídicas e, ainda que sob outra perspectiva, também nas historiográficas. Para tanto, buscamos, através da análise dos textos dos poemas, destacar as passagens que se referem ao próprio "rei sábio", a seus familiares e antepassados, bem como a outros reis e imperadores, sejam estes descritos de forma explícita ou não. Isso nos permitirá, em um segundo momento da pesquisa, considerar a possibilidade dessa obra ter sido composta com o objetivo, entre outros, de atuar como instrumento de propaganda real ${ }^{10} \mathrm{e}, \mathrm{com}$ isso, de legitimação do poder.

Mais de 40 cantigas mencionam Afonso $X$ ou outros reis e imperadores, sendo que, das referentes a Afonso ${ }^{11}$, pelo menos nove teriam sido escritas por ele mesmo ${ }^{12}$. Com o intuito de facilitar a análise, agrupamos as cantigas selecionadas com base nessas menções de acordo com os seguintes tópicos: a) intitulação real e pretensão imperial; b) ascendência, linhagem escolhida e origem divina; c) proteção divina; d) concepção do poder real (existência ou não de uma monarquia sagrada).

\section{INTITULAÇÃO REAL E PRETENSÃO IMPERIAL}

As Cantigas de Santa Maria contém dois prólogos, o que é uma característica bastante peculiar da obra. Chamados de Prólogo A e Prólogo $\mathrm{B}$, os dois poemas possuem caráter diverso provavelmente devido 
à sua funcionalidade: o Prólogo A pretende apresentar o autor da obra ${ }^{13}$, o rei Afonso X, e o Prólogo B expõe a justificativa da obra. Redigido em primeira pessoa, o Prólogo B apresenta as intenções de Afonso em caracterizar-se como trovador da Virgem. Para o tópico em questão, o Prólogo A é de especial interesse, já que fornece duas informações importantes acerca da posição de Afonso como monarca. Nas quatro primeiras estrofes, lê-se a intitulação real:

\author{
Don Affonso de Castela, \\ de Toledo, de Leon \\ Rey e ben des Conpostela \\ ta o reyno d'Aragon, \\ De Cordova, de Jahen, \\ de Sevilla outrossi \\ e de Murça, u gran ben \\ lle fez Deus, com'aprendi, \\ Do Algarve, que gãou \\ de mouros e nossa ffe \\ meteu y, e ar pobrou \\ Badallouz, que reyno é \\ Muit' antigu', e que tolleu \\ a mouros Nevl'e Xerez, \\ Beger, Medina prendeu \\ e Alcala d'outra vez ${ }^{14}$.
}

A fórmula utilizada, apesar de não ser idêntica, é semelhante às de outras compilações do scriptorium de Afonso $\mathrm{X}^{15}$. Ela nos informa sobre a multiplicidade do domínio do "rei sábio", constituído não por um único reino unificado, mas por oito reinos menores: Castela, Toledo, Leão, Córdova, Jaén, Sevilha, Múrcia e o Algarve. Também faz uma referência indireta à Reconquista do antigo reino visigodo aos mouros e demonstra uma preocupação em mencionar mais diretamente a participação de Afonso nesse processo. No entanto, a Reconquista da península ibérica praticamente cessa por completo no reinado anterior ao de Afonso X, com a conquista de Sevilha ${ }^{16}$. Os reinos enumerados no poema foram conquistados pelos antecessores de Afonso X: o reino de Toledo foi conquistado por Afonso VI de Leão e Castela em 1085; Fernando III, pai de Afonso X, conquistou Córdova em 1236; Jaén em 1246 e Sevilha em 1248; Múrcia foi conquistada em 1243-1244, quando Fernando III enviou o, então, infante Afonso para receber a homenagem do 
rei mouro de Múrcia e tomar posse do reino, única participação efetiva, ainda que indireta, de Afonso na Reconquista; por último, temos o Algarve, que não aparece na intitulação de Fernando III nem na de Afonso $\mathrm{X}$ antes de $1261^{17}$. O "rei sábio" não é o protótipo do "rei conquistador", herdeiro da tradição visigoda de reis guerreiros, mas pretende passar essa imagem ao incluir-se no processo de Reconquista neste Prólogo A, através de um evidente recurso legitimador e propagandístico.

Ao enumerar os reinos de Afonso $X$, o autor do poema põe em destaque a extensão de seus domínios: "desde Compostela até o reino de Aragão" "is; no sul, até Sevilha e Córdova. Como afirma O'Callaghan, "trata-se de uma forma de sugerir que a grandeza de seu poder e prestígio derivava do fato de que tantos reinos estivessem submetidos a seu mandato" 19 . Além disso, menciona o "grande bem que Deus lhe fez" em Múrcia ${ }^{20}$, atribuindo a conquista à intervenção divina e refletindo a imagem de um rei que goza de proteção especial. A quinta estrofe faz a única menção, em toda a obra, à candidatura de Afonso $\mathrm{X}$ ao trono do Sacro Império 21: "E que dos Romãos Rey/ é per dereit' e Sennor".

De acordo com o costume imperial germânico, aquele que fosse eleito ao trono do Sacro Império era chamado rex Romanorum (rei dos romanos) até que fosse coroado pelo Papa. Só então, após a cerimônia de coroação, ele recebia o título de Imperador. Afonso $\mathrm{X}$ foi eleito pelos príncipes germânicos em 1257, mas não chegou a ser coroado; por isso, nunca referiu-se a si próprio como Imperador, mas como Rei dos Ro$\operatorname{manos}^{22}$. No entanto, o fato de manter este título poderia indicar que ele realmente mantinha a sua pretensão imperial, ou ao menos que se tratava de uma questão de prestígio.

\section{ASCENDÊNCIA, LINHAGEM ESCOLHIDA E ORIGEM DIVINA}

Diversas cantigas mencionam membros da família e antepassados de Afonso X. Além daquelas que narram curas milagrosas de doenças, das quais trataremos mais adiante, temos neste tópico os exemplos das cantigas $122,292,361$ e 376.

$\mathrm{Na}$ primeira delas, encontramos uma referência ao "Emperador, $o$ que de tod' Espanna foi sennor"23. Apesar de não haver menção a seu nome, sabemos que se trata de Afonso VII, que se coroou como imperador da Espanha em $1135^{24}$. A cantiga 69 também se refere a Afonso VII como "Emperador d' Espanna"25. 
A cantiga 292 narra o traslado dos restos mortais de Fernando III e Beatriz da Suábia, pais de Afonso X, para Sevilha, onde o "rei sábio" mandou fazer uma sepultura "mui rica". O poema começa com uma exaltação das qualidades de Fernando III: "o bon rei Don Fernando, que foi comprido de prez, d'esforç'e de grãadeza e de todo ben, sen mal". Além disso, ressalta que ele "sobre tod'outra cousa (...) amava Santa Maria" e que a lealdade dele para com ela era recíproca, pois que ela "en todolos seus feitos atan ben o ajudou" e ele "sempre a servia e a sabia loar"26.

O terceiro exemplo, a cantiga 361, conta que Afonso X mandou colocar uma imagem da Virgem Maria no mosteiro de Las Huelgas de Burgos, erigido por seu bisavô, Afonso VIII, "aquel que primeira vez vençeu o sennor dos mouros pola fe de Deus creer"27. Este antepassado de Afonso X também aparece na cantiga 221 , na qual há uma menção a seu casamento com Eleanor, filha de Henrique II da Inglaterra, e à invasão da Gasconha: "filla del Rei d' Ingraterra, moller del Rei Don Alffonsso, por que el passou a serra e foi entrar en Gasconna pola gannar per guerra"28.

A cantiga 376 menciona o infante D. Manuel, irmão de Afonso X. A passagem sublinha o fato de que Manuel amava muito o rei e que "en servi-lo sa vida el avia despenduda"29.

Esses exemplos de referências - e são apenas exemplos, os mais significativos - indicam o apreço do rei aos feitos de seus antepassados, principalmente de seu pai, Fernando III, que é descrito como um rei bondoso, honrado e piedoso. A cantiga 376 aponta para a relação de fidelidade existente entre Afonso X e seu irmão, o infante D. Manuel. Essa descrição de D. Manuel poderia ser interpretada como uma forma de contrapor sua lealdade para com Afonso aos problemas que o rei enfrentou com seus outros irmãos: o infante Enrique, que desafiou o rei nos primeiros anos de seu reinado e foi enviado ao exílio; o infante Felipe, que liderou a oposição da nobreza e também foi exilado em Granada, mas posteriormente perdoado em 1273; e o infante Fadrique, que o próprio rei mandou executar em $1277^{30}$.

Dentre os exemplos citados, destacamos em especial a menção a Afonso VII como "imperador de toda a Espanha", na cantiga 122. Segundo O'Callaghan, essa referência poderia estar relacionada com a pretensão do próprio Afonso X em ser finalmente coroado (após a eleição) ao trono do Sacro Império, mas também reflete o desejo do rei de governar toda a Espanha: "a alusão a Afonso VII como o "primeiro imperador da Espanha' sugere que Afonso X seria o segundo" 31 .

Também é interessante o trecho da cantiga 221 que menciona o casamento de Afonso VIII com a filha do rei da Inglaterra. A intenção 
de demonstrar o laço entre as dinastias é clara, também exercendo a função de elemento legitimador da linhagem de Afonso X e do seu poder. Ainda neste tópico relacionado à família de Afonso, há uma passagem na cantiga 200 que merece atenção por se referir - ainda que de forma menos direta do que na cantiga 221 - à linhagem real, à ascendência do governante: "ca a mi de bõa gente fez viir direitamente e quis que mui chãamente reinass' e que fosse rei" 32 . Com essa expressão, o rei fornece uma das muitas justificativas para que a Virgem Maria fosse por ele louvada, pois além de tê-lo feito descender de "bõa gente", teria sido ela quem the havia feito rei. Também há menção a uma origem divina de seu reinado na cantiga 401: "E ainda te rogo, Virgen, bõa Sennor, que rogues a teu Fillo (...) pois Rey me fez, queira que reyn' a seu sabor, e de mi e dos reynos seja el guardador, que me deu e dar pode quando ll' en prazer for" ${ }^{\prime 33}$. Neste trecho, além de atribuir seu poder a Deus, o rei ainda complementa afirmando que a ampliação de seus domínios depende da vontade divina. Já a cantiga 409 não se restringe apenas ao reinado de Afonso X, comentando que "Reis e emperadores todos comualmente a todo seu ciente deven de bõa mente dar-lle loores [à Virgem], ca per ela sennores son de toda a gente" 34 .

A crença em uma origem divina da monarquia é uma das imagens teocêntricas do poder real, a qual, "mediante o estabelecimento de um elo de relação direta entre a divindade e o monarca, (...) [revela] uma funcionalidade religioso-política concreta no poder real e em seu representante máximo". Esta concepção "constituía a base fundamental de toda a teologia política vigente em Castela na Baixa Idade Média" ${ }^{35}$. Já a consideração da linhagem real como particularmente escolhida por Deus para ser origem dos diversos monarcas é uma das imagens sacralizadoras da monarquia - inclusive em Castela, ainda que não seja das formas mais abundantes nos textos da época - "tendo recebido tal linhagem uma contínua proteção divina para assegurar sua preservação e evitar sua interrupção, remontando-se em todo caso sua procedência histórica a tempos remotos, sendo esta antigüidade garantia de legitimidade"36.

\section{PROTEÇÃO DIVINA}

Um dos aspectos que mais se destacam neste tópico é o constante pedido do rei à Virgem Maria para que o ajude nos conflitos contra os mouros e a sua efetiva intervenção milagrosa nos casos concretos de confrontamento. Na obra, há dois tipos principais de cantigas, as de loor 
(cantigas de louvor à Virgem), e as de miragre (cantigas narrativas de milagres da Virgem). Algumas cantigas de loor, cujo caráter, em princípio, é essencialmente lírico, trazem, em sua última estrofe, uma intervenção em primeira pessoa rogando por proteção pessoal e para o reino. Exemplos destes loores são os de número 180 e 360 , mas também há casos semelhantes em miragres, como o de número 229.

$N a$ cantiga 180, o eu-lírico surge na última estrofe dizendo: " $E$ poren lle rogo que queir' amparar a mi de mal e Leon e Castela".37. Na 360 , a referência aos mouros é explícita: "E por aquesto te rogo, Virgen santa corõada, pois que tu es de Deus Filla e Madr' e nossa vogada, que esta merçee aja por ti de Deus acabada, que de Mafomet a seita possa eu deitar d'Espanna"38. A cantiga 229 narra como a Virgem Maria defendeu sua igreja em Vila Sirga do ataque dos mouros na época do rei Afonso IX de Leão. No último verso, novamente aparece a intervenção do eu-lírico rogando: "poren mercee lle peço que queira defender-mi"39. Este verso aparentemente não apresenta relação com o milagre narrado, mas considerando os exemplos anteriores e o fato de que o milagre se dá no contexto de um ataque mouro, podemos interpretar esse pedido de proteção justamente como nos casos de confronto, cujo exemplo mais representantivo é o da cantiga 169.

Este poema faz referência à revolta dos mudéjares em $1264-66^{40}$, especificamente na região de Múrcia, e à maneira como o conflito foi resolvido pelo rei com a ajuda de seu sogro Jaime I, rei de Aragão. O milagre narrado gira em torno de uma igreja localizada no bairro mouro de Múrcia, a qual foi poupada da destruição diversas vezes e por diversos motivos, inclusive pela intervenção da Virgem Maria. A última estrofe se destaca pelo papel atribuído a Maria nas conquistas de Afonso X, ou pelo menos nas suas intenções de expandir seus domínios: "E porend' a eigreja sua quita é ja, que nunca Mafomete poder y averá; ca a conquereu ela e demais conquerrá Espanna e Marrocos, e Ceta e Arcilla"'sl. Nessa passagem, fica evidente o projeto do rei de realizar uma Cruzada à África e conquistar o Marrocos. Este projeto, segundo afirma O'Callaghan, foi definitivamente abandonado por Afonso com a revolta dos mudéjares, ${ }^{42}$ mas, de acordo com o que se pode depreender dessa cantiga, o desejo de conquista ainda permanecia mesmo após a resolução do conflito.

Outro aspecto a ser destacado é em relação às repetidas curas consideradas milagrosas da enfermidade de Afonso X. Sobre a natureza da doença não há propriamente uma unanimidade entre os historiadores: sabe-se, pelas fontes, que o rei sofria de uma febre intermitente; segundo Presilla e Kinkade, o rei provavelmente sofria de um tipo de câncer 
de pele, o carcinoma espinocelular; no entanto, também cogita-se um forte reumatismo ${ }^{43}$. Qualquer que fosse a enfermidade, o que nos interessa nesta questão é o milagre narrado da cura em favor do rei. Dentre as cantigas que mencionam as doenças de Afonso, as mais significativas são as de número 209 e 279, que apresentam o milagre narrado em primeira pessoa, e a cantiga 235 , que narra diversos acontecimentos importantes do reinado, além de descrever sua enfermidade ${ }^{44}$.

Na cantiga 209, considerada como a mais pessoal do cancioneiro mariano de Afonso $\mathrm{X}$, o rei descreve seu próprio sofrimento ao adoecer em Vitoria e conta como foi salvo pelo poder da Virgem. O refrão preconiza: "Muito faz grand' erro, e en torto jaz, a Deus quen lle nega o ben que lle faz." $\mathrm{E}$ continua na primeira estrofe: "Mas en este torto per ren non jarei que non cont'o ben que del recebud' ei per ssa Madre Virgen, a que sempr'amei, $e$ de a loar mais d'outra ren me praz." Aqui já temos dois elementos interessantes. O primeiro é a relação feita entre o fato de contar o milagre e o reconhecimento do bem recebido de Deus, sendo a negação desse bem considerada um "grande erro"; ora, Afonso X, enquanto eu-lírico, afirma não querer incorrer neste erro deixando de contar o milagre. O segundo diz respeito ao próprio milagre (ou "bem") recebido de Deus através da Virgem Maria, evidenciando seu papel de medianeira e advogada dos homens perante Deus, característica tantas vezes a ela atribuída nas cantigas.

Segue-se então a narração da doença em Vitoria, ocasião em que o rei dispensou os médicos e mandou que lhe trouxessem o livro das Cantigas de Santa Maria e o pusessem sobre ele, que foi curado logo em seguida. Destacamos aqui o poder atribuído ao livro, receptáculo do poder de Maria. Segundo afirma Corti, em seu estudo sobre as iluminuras das cantigas referentes a enfermidades, "(...) a Virgem se manifesta através de um livro que contém curas milagrosas, textos e música. Da função curativa destes três meios de expressão da religiosidade mariana, será testemunho o milagre." $\mathrm{O}$ autor também aponta que "o fato de abrir $\mathrm{o}$ livro implica a revelação de um conteúdo sacro e ao mesmo tempo misterioso, de algo sobrenatural e, por isso, dotado de poderes superiores. Para Afonso, tais poderes não podiam emanar senão de Deus"45.

Ainda na cantiga 209 , é interessante observar o que nos dizem os versos 37-40:

Quand' esto foi, muitos eran no logar que mostravan que avian gran pesar de mia door e fillavan-s' a chorar, estand' ante mi todos come em $a z^{46}$. 
Este trecho salienta o apreço dedicado ao rei e como sua enfermidade transtornava seus servidores. Ainda na última estrofe, todos os presentes louvam a Virgem pela "mercee" que fez ao rei. Em seu estudo, Corti busca complementar as informações fornecidas pelo texto com as que podem ser depreendidas da iluminura que ilustra esta cantiga. Dessa forma, o autor destaca o fato de o rei estar vestido apenas com uma fina camisa nos primeiros quadros da iluminura, mas, "produzida a cura milagrosa, Afonso recupera imediatamente sua vestimenta de pompa, signo de poder político e de sua reintegração ao mesmo"47.

Como já mencionado acima, outra cantiga narrada em primeira pessoa e que trata de uma ocasião em que Afonso $X$ adoeceu é a de número 279. Já no refrão deste poema, surge o eu-lírico rogando à Virgem por proteção: 'Santa Maria, valed', ai Sennor, e acorred' a vosso trobador, que mal le vair"48. Apesar de não ser tão pessoal como na cantiga 209 , a descrição da doença do rei neste poema apresenta alguns detalhes interessante, como nos versos: "(...) a tan gran mal e a tan gran door, como soffr' este vosso loador (...)" " “(...) seede-mi ora bõ' ajudador en est' enssay que me faz a mort', ond' ei gran pavor (...)". Destacamos nestes trechos a representação do rei em sofrimento e a menção ao medo da morte. Outro fator de interesse no poema é o fato de não haver des. crição do milagre da cura e nem um desfecho de louvor pela realização do milagre, como ocorre na cantiga 209. Na última estrofe, o eu-lírico dá lugar a um narrador impessoal: "Que fez enton a galardõador de todo ben e do mal sãador? Tolleu-ll' a fever e aquel umor mao e lai".

Por fim, mencionamos ainda a cantiga 235. Por ser riquíssima em detalhes sobre acontecimentos históricos do reinado de Afonso X, principalmente no que diz respeito a seus conflitos com a nobreza, esta cantiga já foi objeto de diversos estudos. Dessa forma, não pretendemos abordar aqui toda a gama de possibilidades de interpretação que ela oferece. No entanto, destacamos, além da cura milagrosa das doenças do rei em Requena, Montpellier e Vitoria, onde "o guareceu a Virgen Santa Maria, como Sennor mui leal" 4 , também a proteção que a Virgem lhe dá contra seus inimigos. A segunda estrofe reforça a devoção de Afonso, que "Santa Maria mui de coraçon de pran loava mais d' outra cousa, e non prendia affan en servi-la noit'e dia, rogando seu bon talan que morress'en seu serviço". Este trecho justifica o apoio que o rei recebe da Virgem nas situações narradas a seguir: "Hua vez dos ricos-omes que (...) se juraron contra ele todos que non fosse Rey, seend'os mais seus parentes, que divid'é natural"; "Ca os mais dos ricos-omes se juraron (...) por deitaren do reyno e que ficasse por seu, que xo entre ssi partissen". Estes trechos são referências 
evidentes à revolta da nobreza no período final do reinado de Afonso X, e a forma como os eventos são descritos e como a Virgem protege o rei "ca deles ben o vingou" - demonstram o caráter de traição que o conflito assumia perante os olhos do rei. É interessante observar que as tentativas de usurpação do poder por parte dos "ricos-omes" são sempre descritas como malogradas devido à intervenção de Maria e de Deus, como no trecho "mas de fazer lles foi greu, ca Deus lo alçou na cima [a Afonso] e eles baixou no val [aos traidores]", denotando uma manipulação dos fatos com uma provável intenção propagandística.

O mesmo motivo aparece nas cantigas 200 e 300 :

\section{(...) nas grandes enfermidades \\ [a Virgem] m' acorreu; por que sabiades \\ que poren a servirey.}

Edos que me mal querian

e bscavan e ordian

deu-lles o que merecian, assi como provarei. ${ }^{50}$

E por esto lle demando [à Virgem]

que lle non venna emente do que diz a maa gente porque sõo de seu bando

(...)
Mas que lles dé galardões
ben quaes eles merecen,
porque me tan mal gradecen
meus cantares e meus sões
(...)
E ar aja piadade
de como perdi meus dias
carreiras buscand'e vias
por dar aver e herdade
u verdad'e
lealdade
per ren nunca puid'achar,
mais maldad'e
falssidade
con que me cuidan matar


A questão dos milagres operados em favor do monarca e da proteção divina de que ele gozava está diretamente relacionada à crença de uma origem divina do rei e da realeza. Nieto Soria afirma que "uma vez aceita esta condição [da origem divina], a monarquia tratou de tirar todas as consequiências possíveis dessa circunstância em favor de suas pretensões políticas". Dessa forma, "o rei adquiria o caráter de especial protegido da divindade, o que incluía não somente a sua pessoa, mas também (...) seus direitos políticos e jurídicos" ${ }^{252}$. $\mathrm{O}$ autor questiona se, dentre os privilégios que o rei recebia em função de seu vínculo com a divindade, estaria também a capacidade de operar milagres. E é esta a questão a ser abordada no próximo e último tópico deste estudo.

\section{CONCEPÇÃO DO PODER REAL: MONARQUIA SAGRADA?}

Para responder à questão levantada por Nieto Soria, devemos prmeiro compreender a concepção afonsina de milagre. Na primeira Partida, estão dadas as quatro condições para que um milagre seja considerado como tal:

- que se produza pelo poder de Deus;

- que se manifeste por produzir algo contra a natureza;

- que seja consequiência de merecimento de santidade e bondade que haja em si aquele que o faz ou aqueles por quem é feito;

- que sirva para a "confirmação da fé"

Com base no texto da primeira Partida, Nieto Soria afirma não parecer "provável que houvesse uma crença dentro da própria monarquia de que alguém possuísse por si próprio a capacidade de operar milagres, que era o que se pretendia para os reis da França e da Inglaterra" ${ }^{4}$. Da mesma forma, "a referência a milagres relacionados com a intervenção real poderia ter uma finalidade propagandística evidente: demonstrar a bondade, quando não a santidade de quem era objeto do milagre ou de quem atuava como seu mediador"s5.

Dentro deste contexto, encontramos o caso bastante peculiar da cantiga 321 . O poema narra a história de uma menina de Córdova que padecia de uma enfermidade na garganta "a que chaman lanparões" A mãe da menina procurou diversos médicos, que não conseguiram curála com nenhum medicamento, até que um "ome bõo" lhe aconselhou que o acompanhasse e levasse a filha à presença do rei para curá-la, pois "todo-los reis crischãos an aquesto por vertude que sol que ponnan sas 
mãos sobre tal door, saude an". O homem então contou ao rei o problema e este lhe responde: "Amigo, a esto que me dizedes vos respond'assi e digo que o que me consellades sol non val un mui mal figo, (...) ca dizedes que vertude ei, dizedes neicidade" ${ }^{57}$. O rei afirma que não tem o poder de cura e a solução por ele oferecida é, naturalmente, a cura pela Virgem: a menina deve lavar a estátua de Maria com Cristo após a missa e tomar, por cinco dias seguidos - pois cinco são as letras "achadas eno nome de Maria" -, a água utilizada para lavar a estátua no cálice que se encontra sobre o altar, " $u$ se faz o sangui de Deus do v? o da $v$ ? a".

A questão da sacralização da monarquia em Castela tem sido bastante discutida entre os historiadores. Utilizando esta cantiga como exemplo, podemos constatar diferentes formas de interpretação do referido poema, considerando-se sua inserção no contexto baixo-medieval castelhano. Ruiz, por exemplo, afirma que, nessa cantiga, "Afonso $\mathrm{X}$ ridiculariza as pretensões taumatúrgicas dos reis franceses e ingleses e oferece, como alternativa, o que Américo Castro chamou de magia judaico-muçulmana", e segue, destacando a afirmação de Afonso de que os reis não têm poder de cura e o fato de que o "rei sábio", com seu sabido interesse pela ciência e pelo oculto "preferiria confiar no conhecimento mágico do Oriente (que para ele era racional e científico) do que nas mãos de um rei" 58 . Em seu estudo, Ruiz assinala a ausência de ritos de unção, consagração e coroação ${ }^{59}$ no que diz respeito aos reis castelhanos da Baixa Idade Média, ressaltando a permanência, na península, de rituais de origem germânica herdados dos visigodos.

Em contrapartida, Nieto Soria desenvolveu uma série de estudos com enfoque em outros aspectos que seriam passíveis de conferir o caráter sagrado à monarquia castelhana e que não eram necessariamente os ritos observados na França e na Inglaterra. $\mathrm{O}$ autor considera que o sagrado, em sua dimensão puramente teológico-religiosa, somente adquire tal caráter como consequiência de um ato de consagração mediado exclusivamente por clérigos, o que poderia ser uma limitação do significado da sacralidade monárquica e uma simplificação de algo que, na verdade, era muito mais complexo. De fato,

Não se pode esquecer que falar, em qualquer hipótese, da sacralidade da realeza não deixa de ser referir-se a uma das manifestações mais extraordinárias de todo um processo de manipulação ideológica do qual se podiam deduzir efeitos políticos muito variados e que, ao menos no final da Idade Média, se tinha consciência, pelo menos no ambiente régio, dessa dimensão manipulado- 
ra, o que teve como resultado o impulso de uma ideologia da realeza sagrada que não se baseava em nenhum ato litúrgico de consagração, mas que pretendia justificar, e de fato justificou, para aqueles que assim o aceitaram - entre eles o próprio papa -, o caráter de pessoa sagrada de um rei que não havia recebido nenhuma forma de consagração litúrgico-eclesiástica ${ }^{60}$.

Rucquoi critica tanto Ruiz como Nieto Soria, alegando que ambos analisam o caso castelhano partindo de uma comparação com os modelos francês e inglês, ora procurando afirmar as diferenças, ora as semelhanças ${ }^{61}$. O'Callaghan, assim como Rucquoi, defende o caráter secular adquirido pelos reis castelhanos ao longo da Idade Média. Especificamente sobre o caso da cantiga 321 , dentro do contexto do poder taumatúrgico dos reis, O'Callaghan afirma acreditar que o fato de Afonso $X$ repudiar o poder de cura atribuído a ele e a todos os reis cristãos reflete um ceticismo natural. Sua visão coaduna com a de Ruiz ao constatar que Afonso

era um homem (...) muito interessado pela ciência, e que, ao mesmo tempo em que estava disposto a reconhecer, nas cantigas, que muitos milagres eram realizados pela Virgem Maria, não estava preparado para pretender o poder de cura para si próprio, nem para reconhecê-lo em outros monarcas, cujas fraquezas humanas ele conhecia bem ${ }^{62}$.

Nieto Soria não acredita que a intenção de Afonso fosse negar a existência de alguma relação entre o rei e a ação milagrosa, no caso castelhano, mas sim de considerar como superstição "qualquer crença na virtude milagrosa inata ao ministério régio no caso de qualquer monarca, castelhano ou não, remetendo tal faculdade a um plano celestial" 63 . Além disso, o autor considera também a possibilidade de interpretar esta cantiga

como um indício de que, apesar de tudo, existia em Castela alguma forma de crença popular na capacidade do rei para operar milagres, o que, mesmo na ausência de ritos sistemáticos que a justificasse, não seria tão estranha como crença popular no contexto mental da época. Por outro lado, a remissão da origem do milagre a uma referência celestial seria coerente com o conceito de milagre expresso na primeira Partida ${ }^{64}$. 


\section{CONCLUSÃO}

As questões levantadas neste estudo pretendem lançar uma reflexão diferenciada sobre uma obra que, apesar de já haver sido bastante explorada, parece inesgotável. Quais teriam sido as motivações que levaram Afonso $\mathrm{X}$ a empreender a compilação das Cantigas de Santa Maria? Considerando que os poemas foram musicados e eram executados publicamente - como se pode depreender, entre outros, do último testamento do "rei sábio"65 -, pode-se imaginar que, para o século XIII, as cantigas tinham uma ampla divulgação. Como ignorar o poder legitimador e propagandístico de um conjunto de narrativas piedosas e louvores à Virgem? Tanto a devoção de Afonso, expressa no primeiro plano dos poemas, quanto seu interesse artístico-científico, evidenciado pela variada constelação de suas obras, podem ser observados sob o ponto de vista político. Assim, as cantigas difundem a imagem de um rei legítimo - pois descende de alta linhagem e recebeu seu poder de Deus (através da Virgem) -, devoto e piedoso - pois reitera repetidamente sua gratidão pelos bens que the foram concedidos e procura retribuí-los com seu "trobar" -, e sábio - pois recebeu de Deus a sabedoria e o "entendimento" necessários para levar a cabo a maior de suas empresas artísticas e um dos grandes monumentos da Europa do século XIII.

\section{NOTAS E REFERENCIAS}

1. Sobre a questão da autoria das Cantigas, vide, entre outros, METTMANN, Walter. "Algunas observaciones sobre la génesis de la colección de las Cantigas de Santa Maria y sobre el problema del autor". In: KATZ, Israel e KELLER, John E. (eds.). Studies on the Cantigas de Santa Maria: Art, $\mathrm{Mu}^{-}$ sic and Poetry. Madison: Hispanic Seminary of Medieval Studies, 1987, p. 355-366; e SCARBOROUGH, Connie. "Autoría o autorías". In: MARTÍNEZ, Jesús M. \& RODRÍGUEZ, Ana D. (coords.). El Scriptorium Alfonsí: de los libros de Astrología a las Cantigas de Santa María. Madrid: Editorial Complutense, 1999, p. 331-337.

2. Todos os quatro manuscritos são datados do século XIII, a saber: códice j.b.2 do Escorial (E); códice T.j.I, também do Escorial (T); Códice de Toledo, primitivamente na Biblioteca do Cabido de Toledo, hoje na Biblioteca Nacional, Madrid (To); e manuscrito da Biblioteca Nazionale, Florença $(F)$. Para uma descrição detalhada dos códices, vide introdução de METTMANN, Walter (ed.). Cantigas de Santa Maria (Acta Universitatis Conimbrigensis). Coimbra: Universidade de Coimbra, 1959, 4 vols., edição utilizada como referência para este estudo e doravante citada como CSM, seguida do nú- 
mero do poema (em algarismos arábicos) e do número do volume (em algarismos romanos), com as respectivas páginas.

3. O termo "obra" foi aqui utilizado em oposição a "antologia", que seria o caso dos cancioneiros profanos de poetas galego-portugueses (Cancioneiro da Biblioteca Nacional, Cancioneiro da Ajuda, Cancioneiro da Vaticana). Dessa forma, pretendemos deixar clara uma das diferenças existentes entre as Cantigas de Santa Maria e os demais cancioneiros, qual seja, a de possuir uma estrutura (loores sendo intercalados por miragres) e de não ser uma compilação posterior à sua época mas, ao contrário, contemporaneamente realizada com um propósito e sob orientação determinada (a de Afonso X).

4. O'CALLAGHAN, Joseph F. El rey sabio: el reinado de Alfonso X de Castilla. Trad. Manuel González Jiménez. Sevilla: Universidad de Sevilla, 1996; IDEM. Alfonso X and the Cantigas de Santa Maria-A Poetic Biography (The Medieval Mediterranean, vol. 16). Leiden, Boston, Köln: Brill, 1998.

5. BURNS, Robert I. "The Cantigas de Santa Maria as a Research Opportunity in History". Cantigueiros, n. 1, 1987, p. 17-22.

6. KINKADE, Richard P.. "Alfonso X, Cantiga 235, and the Events of 12691278". Speculum, vol. 67-2 1992, p. 284-323.

7. MONTOYA MARTÍNEZ, Jesús \& JUÁREZ BLANQUER, Aurora. Andalucía en las Cantigas de Santa Maria. Granada: Universidad de Granada, 1988.

8. O'CALLAGHAN, Joseph F.. Alfonso $X$ and the Cantigas..., p. 5-6. A tradução deste trecho e das demais citações de originais em inglês e espanhol é nossa.

9. Sobre a questão da precoce centralização do poder em Castela, vide, por exemplo, RUCQUOI, Adeline. "État, villes et église en Castille à la fin du moyen age". In: BULST, Neithard \& GENNET, J.-Ph. (orgs.). La ville, la bourgeoisie et la genèse de l'État moderne (XIIe-XVIIIe siècle). Paris: Ed. du CNRS, 1988, p. 279-295.

10. É importante destacar a ausência de um paralelo da produção literária de Afonso X com relação a outros governantes europeus da Baixa Idade Média, sobretudo no que diz respeito ao caráter propagandístico da poesia. Há o caso exemplar do Minnesinger Walther von der Vogelweide, o qual escreve canções laudatórias ao imperador Felipe da Suábia de forma a divulgar a imagem de um governante escolhido por Cristo, portanto legitimadora; no entanto, os poemas de Walther demonstram claras pretensões pessoais, como se pode observar após a morte de Felipe, quando o Minnesinger então escreve um poema de protesto direcionado ao imperador por não haver recebido dele um feudo como recompensa pela sua lealdade. $O$ caso descrito encontra-se no artigo de Álvaro Alfredo BRAGANÇA JR., no endereço http:/ /www.ricardocosta.com/alvaro.html. A diferença da poesia de Walther em relação à poesia de Afonso $\mathrm{X}$, ou a ele atribuída, é clara: não se trata de uma auto-propaganda, mas sim de um elogio não isento de interesses pessoais. Ainda sobre este assunto, há a poesia de D. Dinis, de Portugal, neto de Afonso 
X; porém, esta é de caráter essencialmente lírico (cantigas de amor e cantigas de amigo). Sobre a questão mais geral da inclusão de elementos de teoria política e de propaganda real em textos de diversas naturezas, inclusive literária, vide VERGER, Jacques. "Théorie politique et propagande politique". In: CAMMAROSANO, Paolo (org.). La forma della propaganda politica nel due e nel trecento (Collection de l'Ecole Française de Rome, $\mathrm{n}^{\circ}$ 201). Roma, 1994, p. 29-43.

11. E. KELLER, John \& KINKADE, Richard P.. "Iconography and Literature: Alfonso himself in cantiga 209". Hispania (Madrid), $\mathrm{n}^{\circ} 66,1983$, afirmam que "das mais de 400 Cantigas de Santa Maria, cerca de 28 referem-se ao próprio rei ou a membros de sua família que foram beneficiados pela intervenção miraculosa de Nossa Senhora em suas vidas". Os autores consideram esse fato como um "fenômeno notável, pois nenhum outro patrono medieval da literatura e da arte, até onde (...) [se pôde] descobrir, incluiu a si mesmo em um nível tão elevado e de forma tão pessoal em uma obra por ele patrocinada".

12. METTMANN, Walter. "Algunas observaciones...". Um dos indícios que levam Mettmann a crer na autoria de Afonso X dessas cantigas é o discurso em primeira pessoa.

13. Vide notas 1 e 7. Também é interessante lembrar a seguinte passagem extraída da General Estoria: "El rey faze un libro, non por quel lo escriua con sus manos, mas por que compone las razones del, e las emienda, et yegua, $e$ enderesça, e muestra la manera de como se deuen fazer, e desi escriue las qui el manda, pero dezimos por esta razon que el rey faze el libro." General Estoria. Primera parte, ed. Antonio G. SOLALINDE, 477b, apud MARTíNEZ, Jesús M. O cancioneiro marial de Afonso $X$, o Sabio. Santiago de Compostela: Universidade - Servicio de Publicacións e Intercambio Científico, 1991, p. 26.

14. CSM, Prólogo A, I, p. 1.

15. O'CALLAGHAN, J. F. Alfonso $X$ and the Cantigas..., p. 60. Sobre a questão do scriptorium afonsino, vide M. MARTÍNEZ, Jesus. Introducción. In: IDEM \& Ana D. RODRÍGUEZ, El Scriptorium Alfonsí: de los libros de Astrologia a las Cantigas de Santa María. Madrid: Editorial Complutense, 1991.

16. RUIZ, Teófilo. "Expansion et changement: la conquête de Séville et la société castillane (1248 - 1350)" Annales ESC, 3, 1979, p. 548-565.

17. O'CALLAGHAN, J. F.. Alfonso $X$ and the Cantigas..., p. 61-62. Para mais detalhes sobre a disputa entre Portugal e Castela pelo Algarve, ver também, do mesmo autor, El Rey Sabio..., p. 199-206 e A History of Medieval Spain, pp. 368-369, e JIMÉNEZ, Manuel González. Alfonso X El Sabio-Historia de un reinado (1252-1284). Burgos: Editorial La Olmeda, 1999, p. 95-102.

18. A cantiga 367 refere-se a Afonso X como "Rey de Castela e de Santiago de Compostela" (CSM 367, III, 295-297); O'Callaghan aponta que este título nunca foi utilizado em documentos oficiais e que, aparentemente, foi escolhido para 
figurar neste poema devido à necessidade de rima. No entanto, o autor afirma estar convencido de que se trata de "uma afirmação forçada da soberania real sobre o arcebispo" de Santiago, Gonzalo (1273-1281), o qual entrara em conflito com o rei ao recusar-se a render homenagem a ele. Gonzalo foi exilado e o rei "assumiu diretamente o governo do arcebispado e seu senhorio extensivo na Galícia". O'CALLAGHAN, J. F.. Alfonso $X$ and the Cantigas..., p. 190. Vide também LINEHAN, Peter. The Spanish Church and the Papacy in the thirteenth century. Cambridge: Cambridge University Press, 1971, p. 173.

19. O'CALLAGHAN, J. F. El rey sabio..., p. 32.

20. Segundo O'CALLAGHAN, J. F. Alfonso $X$ and the Cantigas..., p. 61, o autor do Prólogo A poderia estar se referindo não à conquista de Múrcia de 1248, enquanto Afonso era infante, mas sim à reconquista de 1266, após a revolta dos mudéjares, com a ajuda de seu sogro, Jaime I de Aragão. Neste caso, o poema poderia ser datado (após 1266).

21. Vide o interessante trabalho de ALVAR, Carlos. "Poesía e política en la corte alfonsî'. Cuademos Hispanoamericanos, $\mathrm{n}^{\circ}$ 410, 1984. Neste estudo, Alvar expõe a recepção do fecho del imperio por partes dos trovadores provençais e ibéricos e a forma pela qual alguns deles apóiam e outros ridicularizam a pretensão imperial de Afonso X.

22. O'CALLAGHAN, J. F. Alfonso $X$ and the Cantigas..., p. 63-65. O autor também menciona que Afonso $X$ utilizou o título de Rei dos Romanos em suas correspondências em latim com o Papa e com seus partidários germânicos e italianos, mas nunca nos documentos da chancelaria castelhana.

23. CSM 122, II, p. 60-62.

24. A cerimônia de coroação de Afonso VII como imperador encontra-se descrita na Chronica Adefonsi Imperatoris e na própria Estoria de Espanna de Afonso X. O'CALLAGHAN, J. F. Alfonso X and the Cantigas..., p. 36.

25. CSM 69, I, p. 204-207.

26. CSM 292, III, p. 110-113.

27. CSM 361, III, p. 282-283.

28. CSM 221, II, p. 302-304.

29. CSM 376, III, p. 314-316.

30. Os motivos da execução de Fadrique e Simón Ruiz permanecem um dos mistérios do reinado de Afonso X. Especula-se que eles tenham conspirado contra o rei, mas há também a possibilidade de que tenham sido punidos por homossexualidade. O'CALLAGHAN, J. F. Alfonso $X$ and the Cantigas..., p. 144-151.

31. O'CALLAGHAN, J. F. Alfonso $X$ and the Cantigas..., p. 36-37; JIMÉNEZ, Manuel González. Alfonso X El Sabio, p. 149.

32. CSM 200, II, p. 254-255.

33. SM 401, III, p. 357-360.

34. CSM 409, III, p. 377-379.

35. NIETO SORIA, José Manuel. Fundamentos ideológicos del poder real en Castilla (siglos XIII-XVI). Madrid: Eudema, 1988, p. 51. 
36. NIETO SORIA, José Manuel . Fundamentos ideológicos..., p. 65-66.

37. CSM 180, II, 199-201.

38. CSM 360, III, $280-281$.

39. CSM 229, II, 323-324.

40. Mudéjares é a forma como eram chamados os mouros que permaneceram na península após a Reconquista, submetendo-se diretamente aos cristãos. O termo deriva de almudajjan, ou seja, "aqueles a quem se permitiu permanecer”. O’CALLAGHAN, J. F.. El Rey Sabio, p. 134.

41. CSM 169, II, 174-176.

42. O'CALLAGHAN, J. F. El Rey Sabio, p. 224.

43. Os trabalhos de Maricel Presilla e Richard P. Kinkade que aprofundam a investigação a respeito da doença de Afonso $X$ encontram-se citados em O'CALLAGHAN, J. F. Alfonso $X$ and the Cantigas..., p. 132.

44. Sobre esta cantiga, vide o excelente trabalho de P. KINKADE, Richard. "Alfonso X, Cantiga 235, and the Events of 1269-1278". Speculum, vol. 67-2, 1992, p. 284-323.

45. CORTI, Francisco. "Narrativa visual de la enfermedad em las Cantigas de Santa María". Cuadernos de Historia de España, Buenos Aires, n. 85, 1994, pp. 85-115. Quanto a esta questão, o autor lembra também o seguinte trecho do Prólogo B: “(...) confiand' em Deus, ond' o saber vem, ca per ele tenno que poderei mostrar do que quero algua ren. E o que quero e dizer loor da Virgen, Madre de nostro Sennor, Santa Maria", no qual fica evidente a emanação do poder e da sabedoria diretamente de Deus.

46. CSM 209, II, p. 274-275.

47. Sobre a iluminura que ilustra a cantiga 209 , vide, além do já citado estudo de Francisco Corti, KELLER, John \& KINKADE, Richard P. "Iconography and Literature: Alfonso himself in cantiga 209". Hispania, n $66,1983$.

48. CSM 279, III, p. 80-81.

49. CSM 235, II, p. 234-238.

50. CSM 200, II, p. 254-255.

51. CSM 300, III, p. 131-132.

52. NIETO SORIA, José Manuel. "Origen divino, espíritu laico y poder real en la Castilla del siglo XIII". Anuario de Estudios Medievales, n 27, 1997, p. 43-101, esp. p. 67.

53. AFONSO X, O SABIO. Las Siete Partidas del Sabio Rey Don Alfonso El Nono. Salamanca: Casa de Andrea de Portonariis, 1565. I, IV, 66, apud NIETO SORIA, José Manuel. "Origen divino...", p. 67.

54. NETO SORIA, José Manuel. "Origen divino...", p. 67. Sobre a questão do poder milagroso de cura atribuído aos reis da França e da Inglaterra, vide o clássico de BLOCH, Marc. Os Reis Taumaturgos - o caráter sobrenatural do poder régio, França e Inglaterra. Trad. São Paulo: Cia. das Letras, 1993.

55. NIETO SORIA, José Manuel. "Origen divino...", p. 67-68.

56. O glossário da edição de METTMANN, Walter (ed.). Cantigas de Santa Ma- 
ria, vol. 4, define "lamparöes" por escrófula, a doença sobre a qual se acreditava que os reis franceses e ingleses tivessem poder de cura.

57. CSM 321, III, p. 183-185.

58. RUIZ, Teófilo F. "Unsacred Monarchy: The Kings of Castile in the Late Middle Ages". In: WILENTZ, S. (ed.). Rites of power. Symbolism, ritual and politics since the Middle Ages. Filadélfia: UPP, 1985, p. 109-144, esp. p. 128.

59. No que diz respeito à coroação, ou melhor, à auto-coroação dos reis castelhanos da Baixa Idade Média, vide, entre outros, o próprio estudo citado de RUIZ, Teófilo F. "Unsacred Monarchy...", p. 109-110; e, especificamente para o caso de Afonso X, O’CALLAGHAN, J. F. El Rey Sabio..., p. 27.

60. NIETO SORIA, José Manuel. "Origen divino...", p. 50-51.

61. RUCQUOI, Adeline. "De los reyes que no son taumaturgos: los fundamentos de la realeza en España". Temas Medievales, Buenos Aires, $n^{\circ}$ 5, 1995, p. 163-186, esp. p. 165-166.

62. O'CALLAGHAN, J. F. Alfonso $X$ and the Cantigas..., p. 81.

63. NIETO SORIA, José Manuel. "Origen divino...", p. 68.

64. NIETO SORIA, José Manuel. “Origen divino...,", idem.

65. Datado de 22 de janeiro de 1284. O documento ordena que "todos los libros de los cantares de loor de Sancta Maria" fossem cantados em suas festividades. O'CALLAGHAN, J. F. El Rey Sabio..., p. 317. Sobre a questão do acesso aos poemas, vide COLRTI, Francisco. "Narrativa visual...", p. 86. 